\title{
Database Marketing Use as a Tool of Knowledge Management within Firms in Albania
}

\author{
Aurela Ramaj \\ Faculty of Economy, University of Vlora "Ismail Qemali", Albania \\ aurelabifsha@yahoo.ca \\ Assoc. Prof. Evelina Bazini \\ Faculty of Economy, University of Vlora "Ismail Qemali" Albania \\ evelina.bazini@univlora.edu.al
}

\section{Doi:10.5901/mjss.2013.v4n11p584}

\section{Abstract}

Today knowledge is considered as the heart of business. The first step of gaining knowledge is gathering data from internal and external sources. Then these data are classified and processed to turn into information. And information is then transformed into knowledge upon which organizational strategies, decisions and actions are built. In the changing conditions of marketing today, marketers see it essential to know their customer base and plan and make marketing strategies and actions based upon this knowledge. This is called database marketing. Customer data are transformed into customer information kept in a marketing database. The aim of this paper is to investigate the application of database marketing as a tool of knowledge management within firms in Albania.

Keywords: database marketing, knowledge management, data, information.

\section{Research Methodology}

This paper is based on primary and secondary data. Primary data are results of a survey research about database marketing use as a tool for knowledge management by large and medium firms in the service sector in Albania. Secondary data are results of literature review and other studies in this field. The study consisted in face -to- face interviews with top management within 34 large and medium firms that operate in Albania. 17 firms were from services sector and 17 firms were from manufacturing sector. Simple random technique was used for sampling so that every firm on the list (Tirana and Vlora list) had equal probability of selection. Questionnaire method was used as survey instrument. The survey was carried out as an enterprise survey, that is data collection and reporting was focused on the enterprise rather then to the establishment. Questionnaire was directed to top management of the companies to get a more realistic view. Reason for selecting top management was that one of the aims of the study was to predict the future of database marketing use as a tool for knowledge management in Albanian's firms. Top management is the only appropriate option to get response on that because they are the ones who know where to take the company in future, what to implement and what not.

The set of database marketing and IT indicators for which data were collected in this survey was organized in the following modules:

- Background information (basic company data, data collection)

- Acquaintance with IT

- The kind and source of customer information they collect

- Their database marketing process

\section{Knowledge and knowledge management}

\subsection{Knowledge}

Following Davenport and Prusak (2000): "Knowledge is a fluid mix of framed experiences, values, contextual information and expert insight that provides a framework for evaluating and incorporating new experiences and information." 
Knowledge originates and is applied in the mind of individuals, whereas in organizations it can be embedded in routines, processes, practices, and norms (Davenport and Prusak 2000). It actively enables performance, problem-solving, decision-making, learning and teaching by integrating ideas, experience, intuition, and skills, to create value for employees, the organization, its customers, and shareholders (Liebowitz 2000; Probst et al. 2000). Commonly agreed, knowledge can be split into two types: explicit and tacit (Polanyi 1997 and Nonaka and Takeuchi 1995). Tacit knowledge is held by experts, having topic specific as well as cognitive skills that contain patterns of thought or notions, beliefs, institution and mental models. Explicit knowledge can be articulated in an artifact of some type outside a human being and be transferred e.g. to non-experts. Explicit knowledge is rational and includes theoretical approaches, problem solving, manuals, and databases. The transfer of knowledge from tacit to explicit or explicit to tacit can be viewed as a continuous learning process becoming the so-called knowledge spiral (Nonaka and Takeuchi 1995; Senge 1990). It enables building and conveying knowledge in need of good "Knowledge Management" to enhance the process, finally leveraging corporate performance.

In the information technology context, knowledge is very distinct from data and information (see Figure 1). Whereas data are a collection of facts, measurements, and statistics, information is organized or processed data that are timely (i.e., inferences from the data are drawn within the time frame of applicability) and accurate (i.e., with regard to the original data) (Holsapple, 2003). Knowledge is information that is contextual, relevant, and actionable.

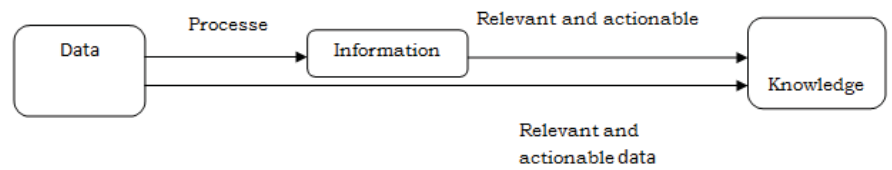

Figure 1. Data, information and knowledge

\subsection{Knowledge management}

The term "knowledge management" seems to have arisen in the mid-70s. Nicholas Henry (1974) uses "knowledge management' in a manner that resembles our current understanding of the expression. Defined broadly, "KM is the process through which organizations extract value from their intellectual assets" (Kaplan, 2002). By adopting this belief of $\mathrm{KM}$, the following definition of KM is suitable. "Knowledge Management caters to the critical issues of organizational adaptation, survival and competence in face of increasingly discontinuous environmental change. Essentially, it embodies organizational processes that seek synergistic combination of data and information processing capacity of information technologies and the creative and innovative capacity of human beings" (Malhotra, 1997).

Knowledge management is a process that helps organizations identify, select, organize, disseminate, and transfer important information and expertise that are part of the organization's memory and that typically reside within the organization in an unstructured manner. This structuring of knowledge enables effective and efficient problem solving, dynamic learning, strategic, planning, and decision making. Knowledge management initiatives focus on identifying knowledge, explicating it in such a way that it can be shared in a formal manner, and leveraging its value through reuse. Through a supportive organizational climate and modern information technology, an organization can bring its entire organizational memory and knowledge to bear upon any problem anywhere in the world and at any time. For organizational success, knowledge, as a form of capital, must be exchangeable among persons, and it must be able to grow. Knowledge about how problems are solved can be captured, so that knowledge management can promote organizational learning, leading to further knowledge creation.

\section{Knowledge Discovery in Databases}

Knowledge discovery in database (KDD) is commonly defined as "the nontrivial process of identifying valid, novel, potentially useful and ultimately understandable patterns in data" (Fayyad et al., 1996). The term "data" is understood as a set of facts or atomic pieces of information (e.g. cases in a database) while "knowledge" stands for a higher-level concept that relates to the properties of the collection of data as a whole (e.g. dependencies among sets of attributes in a database and rules for predicting attribute values). KDD has succeeded very well in marketing field with special focus on direct marketing activities (Buckinx and den Poel, 2005, Buckinx et al., 2007, den Poel and Buckinx, 2005). Indeed, this marketing research area has become an important application field for Database Marketing (e.g., companies or 
organizations try to establish and maintain a direct relationship with their customers in order to target them individually for specific product offers or fund raising, throughout marketing databases exploration). According to the literature, KDD has two main goals which are oriented by users' intensions (Han and Kamber, 2001) (Kuo et al., 2007a):

- Prediction: using available data to predict unknown or future values giving some variables. The main goal of the prescriptive process effort is to automate a decision making process by creating a model capable of making a prediction, assigning a label, or estimating a value. Normally, the model results will be acted upon directly, which makes accuracy the most important measure of performance when evaluating this type of models;

- Description: The primary goal of descriptive data mining is to gain increased understanding of the data in order to find some interesting patterns and presenting it to the user in an easily understood way. Although it often results in actions, these are not the sort of actions that can be automated directly from the results of the model. Besides that, the best model may not be the one that makes the most accurate predictions. Often the insight gained through building the model is the most important part of the process, and the actual results from the model may never be used at all. As main distinction between prediction and description is who interprets the discovered knowledge - the system (in case of prediction) or the user (in case of description) (Fayyad et al., 1996, Piatetsky-Shapiro, 2007, Piatetsky-Shapiro, 1991). However, the Background and Related Work boundary between these two goals is not distinct since some predictive models can be used for description and vice versa (Piatetsky-Shapiro, 1991). KDD has connections with many research fields, such as statistics, database theory and artificial intelligence techniques. Therefore, research themes in KDD are scattered across a range of topics including (Ankerst et al., 2003) (Piatetsky-Shapiro, 2007): data representation, large databases, model pruning and simplification, visualization and quality assessment. Other areas in KDD may include decomposition of the process, development of discretization methods, other pre-processing techniques (in order to ensure data quality) or development of parallel steps in the KDD process, among others.

\section{Database Marketing}

DBM refers to the use of database technology for supporting marketing activities (Leary et al., 2004) (Wehmeyer, 2005) (Pinto et al., 2009). Therefore, it is a marketing process driven by information (Coviello et al., 2001) (Brookes et al., 2004) (Coviello et al., 2006) and managed by database technology (Carson et al., 2004) (Drozdenko and Perry, 2002). It allows marketing professionals to develop and to implement better marketing programs and strategies (Shepard, 1998) (Ozimek, 2004).

There are different definitions of DBM with distinct perspectives or approaches denoting some evolution an evolution along the concepts (Zwick and Dholakia, 2004). From the marketing perspective, DBM is an interactive approach to marketing communication. It uses addressable communications media (Drozdenko and Perry, 2002) (Shepard, 1998), or a strategy that is based on the premise that not all customers or prospects are alike. By gathering, maintaining and analyzing detailed information about customers or prospects, marketers can modify their marketing strategies accordingly (Tao and Yeh, 2003). Then, some statistical approaches were introduced and DBM was presented as the application of statistical analysis and modeling techniques to computerized individual level data sets (Sen and Tuzhiln, 1998)(Rebelo et al., 2006) focusing some type of data. Here, DBM simply involves the collection of information about past, current and potential customers to build a database to improve the marketing effort (Brito and Hammond, 2007). The information includes: demographic profiles; consumer likes and dislikes; taste; purchase behavior and lifestyle (Seller and Gray, 1999) (Pearce et al., 2002).

As information technologies improved their capabilities such as processing speed, archiving space or, data flow in organizations that have grown exponentially different approaches to DBM have been suggested: generally, it is the art of using data you've already gathered to generate new money-making ideas (Gronroos, 1994) (Pearce et al., 2002); stores this response and adds other customer information (lifestyles, transaction history, etc.) on an electronic database memory and uses it as basis for longer term customer loyalty programs, to facilitate future contacts, and to enable planning of all marketing. (Fletcher et al., 1996) (Kurtulus and Kurtulus, 2006)(Frankland, 2007); or, DBM can be defined as gathering, saving and using the maximum amount of useful knowledge about your customers and prospects...to their benefit and organizations' profit. (McClymont and Jocumsen, 2003) (Pearce et al., 2002). Lately some authors has referred DBM as a tool database-driven marketing tool which is increasingly taking centre stage in organizations strategies (Payne and Frow, 2005)(Pinto, 2006)(Lin and Hong, 2008). In common all definition share a main idea: DBM is 
a process that uses data stored in marketing databases in order to extract relevant information to support marketing decision and activities through customer knowledge, which will allow satisfy their needs and anticipate their desires.

During the DBM process it is possible to consider three phases (De Tienne and Thompson, 1996) (Shepard, 1998) (Drozdenko and Perry, 2002): data collection, data processing (modeling) and results evaluation.

The first, Marketing data, consists in data collection phase, which will conduct to marketing database creation with as much customer information as possible (e.g., behavioral, psychographic or demographic information) and related market data (e.g., share of market or competitors information's).

During the next phase, information, the marketing database is analyzed under a marketing information perspective throughout activities such as, information organization (e.g., according organization structure, or campaign or product relative); information codification (e.g., techniques that associates information to a subject) or data summarization (e.g., cross data tabulations).

The DBM development process concludes with marketing knowledge, which is the marketer interpretation of marketing information in actionable form. In this phase there has to be relevant information to support marketing activities decision.

\section{Database Marketing as a Tool for Knowledge Management Use within Firms in Albania.}

Based on the analysis of the data collected from the survey conducted to the 34 large and medium firms (17 in the production sector and 17 in the service sector) in Albania, the following summary of the most importance findings were explored.

\subsection{Firms' acquaintance with IT results}

Both the two group of firms told that they use IT. They all had computer which are consider as a main component of IT tool. However there is a difference among the companies in terms of the quantity (numbers) of personal computers (PCs). that number depends on many factors, for example, company size in terms of employ's number and the company's need and work nature. Further more, there is a difference between the companies in terms of advanced software level and the extend of how to utilize them. According to the research results, in general the amount of money that is spent in training programs, motivation and wages has grown the last three years. Only $3 \%$ of them use IT for micro office, such as word processing, the other part use advanced IT tools for design, quality control, data base system, and so on. They all answered that they looked positively to information and information technology and they all collected customer information. .

\subsection{The kind and source of customer information they collect}

The firms of both groups were asked about the type of customer information they collected. They all mentioned the following information: name and surname, address, telephone number, gender and age, educational level of their customers. Due to the specific nature of the product they offer, some of them collected a more specific information like: the period that customers stayed in the same address, marital status information about their customers, number of people lived with, number of houses owned, geo-demographic information, credit information of their customers, about communication channels preferred, frequency and monetary value of transactions made in the company from the billing department, reasons of shopping, shopping and buying habits of their customers, customer expectations of products, satisfaction from products bought from store.

About the source of customer information they mention the following : eight of them used face to face interaction with customers, twelve used book complaints, twenty used credit card applications, customer cards at the counters, seven used questionnaires filled and knowledge and observation of salespeople. Four of them used online questionnaires. Nine used e-mails as sources of information. Frequency of Internet site visits and time spent there were also used as sources of information. Only five of them used information from third party sources.

\subsection{Their database marketing usage}

The firms of both group were asked whether they had a marketing database. The concept of marketing database was explained as collecting customer information on a database where everyone in the company can reach with the help of a 
computer program.

The firms were asked how frequently they conducted database marketing and the reason for doing so. Database marketing was defined as keeping information about actual and potential customers on a marketing database by using today's computer technology, and then having marketing applications based on analysis of these information. Only $23 \%$ of the firms involved in the research answered that they did not use database marketing. $78 \%$ of the firms were answered that they always conducted database marketing applications. The others were answered that they frequently had database marketing applications. They all agreed that it was hard to conduct database marketing in the full sense because of inadequacy of infrastructure and lack of personnel with adequate knowledge. The firms were asked what they thought database marketing applications would add to their activity. They were to choose among alternative ideas. All of them believed that database marketing would increase their sales, induce customer loyalty, and help find new customers and be more competitive in the market.

\section{Concluding remarks and suggestions}

Knowledge is seen as a driver for the definition and development of an organizational strategy and a key determinant of sustainable organizational competitiveness. The shift to knowledge as the primary source of value means that knowledge plays a key role in the organizational effectiveness. Database marketing, where everything is built upon customer knowledge, is one important tool of knowledge management.

The aim of this paper was to investigate the application of database marketing as a tool of knowledge management within firms in Albania.

The results shows that not all the firms use database marketing. This mean that they cannot be in able to transform customer information to into customer knowledge to build strategies and act upon. Within the knowledge based economy, firms in Albania are facing both opportunities and challenges due to the information and telecommunication technologies development. They should intensify their efforts of promoting the use of database marketing. By integrating IT in their day-to-day activities they will be in able to benefit from opportunities that knowledge based economy offers avoiding the risk of been eliminated from the market due to the competition.

\section{References}

Barney, J. 1991. Firm resources and sustained competitive advantage. Journal of Management, 17:99-120.

Blom, R.R., Hellenthal, F.J., Van Rijnswou, M., \& Warmenhoven, B. 2006. Do you manage your knowledge? Rotterdam, Netherlans: Clearing Center foor Strategy and Entrepreneurship "Le Manageur"/ Study Association EUREOS.

Brookes, R. W., Brodie, R. J., Coviello, N. E., and Palmer, R. A. (2004). How managers perceive the impacts of information technologies on contemporary marketing practices: Reinforcing, enhancing or transforming? Journal of Relationship Marketing, 3(4):7-26.

Buckinx, W. and den Poel, D. V. (2005). Customer base analysis: Partial defection of behaviorally-loyal clients in a non-contractual fmcg retail setting. European Journal of Operational Research, 164 (1):252-268.

Buckinx, W., Verstraeten, G., and den Poel, D. V. (2007). Predicting customer loyalty using the internal transactional database. Expert Systems with Applications, 32:125-134.

Carson, D., \& Gilmore, A. 2000. SME marketing management competencies. International Business Review, 9:363-382.

Carson, D., Gilmore, A., and Walsh, S. (2004). Balancing transaction and relationship marketing in retail banking. Journal of Marketing Management, 20:431-455.

Choo, C., \& Bontis. N. 2002. The Strategic management of intellectual capital and

Coviello, N., Milley, R., and Marcolin, B. (2001). Understanding it-enabled interactivity in contemporary marketing. Journal of Interactive Marketing, 15(4):18-33.

Coviello, N., Winklhofer, H., and Hamilton, K. (2006). Marketing practices and performance of small service firms - an examination in the tourism accommodation sector. Journal of Service Research, 9(1):38-58.

Davenport, T., Prusak, L. (2000): Working Knowledge, Harvard Business School Press, Boston

Davenport, T.H., \& Prusak, L. 1998. Working knowledge. Executive Excellence; $10^{\text {th }}$ September 1998.

den Poel, D. V. and Buckinx, W. (2005). Predicting online-purchasing behavior. European Journal of Operational Research Dirk Van den Poel and Wouter Buckinx, 166(2):557-575.

Desouza, K.C., \& Awazu, Y. 2006. Knowledge management at SMEs: five peculiarities. Journal of Knowledge Management, 10(1): 32-43.

Desouza, K.C., \& Awazu, Y. 2006. Knowledge management at SMEs: five peculiarities. Journal of Knowledge Management, $10(1): 32-43$.

DeTienne, K. B. and Thompson, J. A. (1996). Database marketing and organizational learning theory: toward a research agenda. Journal of Consumer Marketing, 13(5):12-34.

Drozdenko, R. and Perry, D. (2002). Optimal Database Marketing. SAGE Publications, Thousand Oaks, USA.

Drozdenko, R. and Perry, D. (2002). Optimal Database Marketing. SAGE Publications, Thousand Oaks, USA.

Fayyad, U., Piatetsky-Shapiro, G., and Smyth, P. (1996). From data mining to knowledge discovery in databases. In Magazine, A., editor, Al Magazine, volume 17, pages 37-54, Univ. Calif Irvine, Dept Comp \& Informat Sci, Irvine, Ca, 92717 Gte Labs Inc, Knowledge Discovery 
Databases Kdd Project, Tech Staff, Waltham, Ma, 02254. American Association for Artificial Intelligence.

Fletcher, K., Wright, G., and Desai, C. (1996). The role of organizational factors in the adoption and sophistication of database marketing in the uk financial services industry. Journal of Direct Marketing, 10:10-21.

Frankland, D. (2007). How firms use database marketing services. Technical report with user interview data, ForresterResearch Inc.

Gronroos, C. (1994). From marketing mix to relationship marketing:towards a paradigm shift in marketing. Management Decision, 32(2):4-20.

Holsapple, C. W., "Knowledge and its Attributes," in Handbook on Knowledge Management, Volume 1k (ed. C. W. Holsapple). New York: Springer-Verlag, 2003, pp. 165-188.

Leary, C. O., Rao, S., and Perry, C. (2004). Improving customer relationship management through database/internet marketing. European Journal of Marketing, 38(3/4):338-354.

Leary, C. O., Rao, S., and Perry, C. (2004). Improving customer relationship management through database/internet marketing. European Journal of Marketing, 38(3/4):338-354.

Liebowitz, J. (2000): The Knowledge Management Handbook, Department of Information Systems,

Lin, C. and Hong, C. (2008). Using customer knowledge in designing electronic catalog. Expert systems with Applications, 34:119-127.

Lopez, S.P., Montes Peón, José Manuel., \& Vázquez Ordás, Camilo José. 2004. Managing knowledge: the link between culture and organizational learning. Journal of Knowledge Management, 8(6):93-104.

Lopez, S.P., Montes Peón, José Manuel., \& Vázquez Ordás, Camilo José. 2004. Managing knowledge: the link between culture and organizational learning. Journal of Knowledge Management, 8(6):93-104.

Nonaka, I., Takeuchi, H. (1995): The Knowledge-Creating Company: How Japanese Companies Create

organizational knowledge. New York:Oxford University Press.

Ozimek, J. (2004). Case studies: The 2003 information management project awards. Journal of Database Marketing \& Customer Strategy Management, 12(1):55.

Pearce, J. E., Webb, G. I., Shaw, R. N., and Garner, B. (2002). A systemic approach to the database marketing process. ANZMAC Conference Proceedings, 1:2941-2948.

Pinto, F. (2006). A descoberta de conhecimento em bases de dados como suporte a actividades de business intelligence - aplicaÃß̃̃ £o na Ã rea do database marketing. Master's thesis, Universidade do Minho.

Pinto, F., Santos, M. F., and Marques, A. (2009). WSEAS Transactions on Business and Economics, volume 6, chapter Database marketing intelligence supported by ontologies, pages 135-146. World Scientific and Engineering Academy and Society.

Pinto, M, F. and Guarta, T. Database Marketing Intelligence Methodology Supported by Ontologies and Knowledge Discovery in Databases.

Polanyi, M. (1997): The tacit dimension, in Knowledge in Organizations, Butterworths, London, 135 - 146

Probst, G., Raub, S., Romhardt, K. (2000): Managing Knowledge, John Wiley \& Sons, Chichester

Rehman, M. \& Kamil B Mahmood, A. \& Sugathan, S. \& Amin, A. Implementation of Knowledge Management in Small and Medium Enterprises Malaysian Perspective

Senge, P., (1990): The Fifth Discipline: The Art and Practice of the Learning Organization, Currency/Doubleday, August

Shepard, D. (1998). The New Direct Marketing: How to Implement A Profit-Driven Database Marketing Strategy. David Shepard Ass, 3rd edition.

Takeuchi, H., \& Nonaka, I. 2004. Hitotsubashi on Knowledge Management, Singapore: John Wiley and Sons.

Tao, Y.-H. and Yeh, C.-C. R. (2003). Simple database marketing tools in customer analysis and retention. International Journal of Information Management, 23:291-301.

the Dynamics of Innovation, Oxford University Press, May

Thorpe, R., Holt R., Macpherson, A., \& Pittaway, L. 2005. Using knowledge within small and medium-sized firms: a systematic review of the evidence. International Journal of Management Reviews, 7(4):257-281.

Uhlaner L.M. \& Van Santen J. 2007. Organization context and knowledge management in SMEs: A study of Dutch technology-based Firms', in H. Landstrom, M. Raffa, and L. Iandoli (Eds.), Entrepreneurship, Competitiveness and Local Development - Frontiers in European Research, Cheltenham, UK: Edward Elgar Publishing: 170- 199.

Uit Beijerse, R. P. 2000. Knowledge management in small and medium-sized companies: knowledge management for entrepreneurs. Journal of Knowledge Management, 4(2):162-179.

UNDP - report, March 2007. Knowledge Management Toolkit for the Crisis Prevention and Recovery Practice Area

University of Maryland

Van Rijnswou, M. 2005. Knowledge management and performance in SMEs, Master's Thesis, Faculty of Economics.

Von Krogh, G., Ichijo, K., \& Nonaka, I. 2000. Enabling knowledge creation. New York: Oxford University Press

Wehmeyer, K. (2005). Aligning it and marketing - the impact of database marketing and crm. Journal of Database Marketing \& Customer Strategy Management, 12(2):243.

Wehmeyer, K. (2005). Aligning it and marketing - the impact of database marketing and crm. Journal of Database Marketing \& Customer Strategy Management, 12(2):243.

Wiklund, J., \& Shepherd, D. 2003. Knowledge-based resources, entrepreneurial orientation, and the performance of small and medium-sized businesses. Strategic Management Journal, 24:1307-1314.

Wong, W.L.P., \& Radcliffe, D.F. 2000. The tacit nature of design knowledge. Technology Analysis \& Strategic Management, 12(4):493-512.

Zhou, H., Tan, S., \& Uhlaner, L. 2007. Family orientation, strategy and organizational learning as predictors of knowledge management in Dutch SMEs: a quantitative study. EIM, Zoetermeer.

Zwick, D. and Dholakia, N. (2004). Whose identity is it anyway? consumer representation in the age of database marketing. Journal of Macromarketing, 24(1):31-43. 